\title{
Whole-body MRI within a surveillance program for carriers with clinically actionable germline TP53 variants - the Swedish constitutional TP53 study SWEP53
}

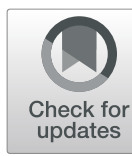

\author{
Meis Omran ${ }^{*^{*}}$ (D) Lennart Blomqvist ${ }^{2,3}$ (D) Yvonne Brandberg $^{4}$ (D) Niklas Pal ${ }^{5,6}$ (D) Per Kogner $^{5,6}$ (D), \\ Anne Kinhult Ståhlbom ${ }^{7}$, Emma Tham ${ }^{8,9+}$ (D) and Svetlana Bajalica-Lagercrantz ${ }^{1+}$ (D)
}

\begin{abstract}
Background: The current guidelines in Sweden regarding individuals with a clinically actionable (i.e. pathogenic or likely pathogenic) germline TP53 variant recommend patients to take part of the national Swedish P53 Study (SWEP53).

Methods: The study comprises a patient registry (mandatory for all participants) and three optional parts: a biobank, a surveillance program and a psychosocial evaluation of the surveillance. All known adult eligible carriers regardless of age are offered to take part of the surveillance program offering MRI yearly of the whole-body, breast, and brain as well as breast ultrasound. A special surveillance program is offered for individuals 15-18 years old with a 50\% risk of being a mutation carrier or with a verified TP53 variation, includes ultrasound of the abdomen and urine corticosteroid profiles. Clinically motivated further examinations are performed upon need. The national inclusion is performed through the six clinical genetic units in Sweden at Umeå, Uppsala, Stockholm, Gothenburg, Linköping and Lund, and the surveillance is mainly performed through the oncology clinics.

Results: To date, a total of 41 adults and 11 children have been included in the study.

Conclusions: The SWEP53 is the first structured national surveillance program including radiological and clinical routines for TP53 mutation carriers in the Scandinavian setting. The aim of this publication is to present and describe the ongoing Swedish surveillance study to encourage the initiation of similar studies and to contribute to the knowledge of adequate clinical handling of these cancer prone families.
\end{abstract}

Trial registration: Trial registration number: ISRCTN13103571, retrospectively registered on 14/10/2019.

Keywords: LiFraumeni syndrome, Germline TP53 mutation, Hereditary breast cancer, Pathological variant, Surveillance program

\section{Background}

The Li-Fraumeni syndrome (LFS) was first described by $\mathrm{Li}$ and Fraumeni in 1969 [1]. LFS is an inherited autosomal dominant cancer syndrome caused by germline variants in the TP53 gene. The syndrome is

\footnotetext{
* Correspondence: meis.omran@ki.se

tEmma Tham and Svetlana Bajalica-Lagercrantz contributed equally to this work.

'Department of Oncology-Pathology, Karolinska Institutet SE-171 77

Stockholm, Sweden AND Cancer Theme, Karolinska University Hospital, Solna, SE-171 76 Stockholm, Sweden

Full list of author information is available at the end of the article
}

characterized by high risk of developing diverse tumours, mainly sarcoma, breast, brain and adrenocortical tumours [2]. Even though LFS caused by a pathogenic germline TP53 variant is rare, pathogenic somatic TP53 variants are the most abundant alteration identified in sporadic cancers, and is reported in $50 \%$ of all human tumours [3].

The prevalence of germline pathogenic TP53 variants is estimated to 1:5000-1:20000 individuals [4], resulting in an estimation of between 500 and 2000 mutation carriers in the Swedish population of almost 10 million

(c) The Author(s). 2020 Open Access This article is distributed under the terms of the Creative Commons Attribution 4.0 International License (http://creativecommons.org/licenses/by/4.0/), which permits unrestricted use, distribution, and 
people. The actual numbers are today unknown and there is no structured TP53 mutation screening or national registry. The estimated life-time cancer risk for female carriers of pathogenic TP53 variants is close to $100 \%$ and the corresponding figure for males is $73 \%$ [5]. The gender difference is usually attributed to the fact that women develop breast cancer [5] [6], while others claim that female mutation carriers are more prone to cancer development regardless of the increased breast cancer risk [7]. In addition, carriers of pathogenic TP53 variants are at risk of developing cancer at considerably younger ages (median age 25 years) than non-carriers. Up to $50 \%$ of all carriers develop a tumour before the age of 30 years $[8,9]$. They are also more prone to develop multiple primary cancers [10]. Fifteen percent of all children will develop cancer before the age of 15 years [11]. In recent years, pathogenic germline TP53 variants have also been found to cause hereditary breast cancer without childhood cancers or classic LFS [12]. The reasons behind these differences in phenotypes are today unknown, and there are no obvious differences in the genetic variants found between these two groups of patients. The European Reference Network, responsible for developing guidelines for germline TP53 variant carriers, are therefore referring to these as hereditable TP53 related cancer syndrome [13].

\section{Surveillance programs}

In 2016, Villani et al [14] presented an 11-year follow-up of the first published surveillance program including whole-body MRI (WB-MRI), showing a five-year overall survival of $88.8 \%$ versus $59.6 \%$ in favour of taking part of the surveillance program compared to non-participants. These results seemed compelling. The study was, however, not randomised due to ethical aspects and there were crossovers between the groups. Further clinical studies are therefore needed to corroborate a potential increase in survival. In addition, more data is needed on the rate of benign and malignant findings in a surveillance program using MRI, as well as the feasibility of the program, including the need of further work-ups and the psychosocial impact of taking part of such a surveillance. A meta-analysis described a risk of false-positive results (defined as benign neoplasms, recurrences of preexisting cancers, and newly diagnosed metastatic cancers) to be $42.5 \%$, but the same study found the rate of new localized malignant findings to be $7 \%$, of whom all were treated with a curative intention [15]. Published data from European surveillance programs [16-18] have been differently designed with regards to follow-up time and inclusion criteria regarding mutational status of individuals $<18$ years old. None of the previously published data from the European studies has had a focus on the evaluation of the psychosocial impact of taking part of a surveillance program.

\section{Current Swedish guidelines}

In Sweden, all patients with pathogenic germline TP53 variants are offered genetic counselling and, in most regions, also the possibility of preimplantation genetic diagnosis (PGD). Besides yearly clinical checkups for all patients, female carriers are offered breast surveillance and/or prophylactic mastectomy. Historically, children in Sweden have not been offered presymptomatic genetic testing as there has not been a specific surveillance program to offer, however children at 50\% risk are offered annual clinical check-ups at a pediatric clinic. The current national guidelines in Sweden now recommend that if surveillance with MRI or ultrasound is offered to TP53 carriers, it should be performed as part of a national Swedish TP53 study named SWEP5 in order to enable a structured evaluation. The study protocol was launched in 2017. The aim of this paper is to present the Swedish surveillance program within the SWEP53 study.

\section{Methods \\ SWEP53 study outline}

The National Swedish TP53 Study SWEP53 consists of four parts. The first part is mandatory for inclusion in the study, whereas participation in parts 2 to 4 is voluntary:

1. National registry: All individuals who consent to participate in the study are included in a national registry containing genetic data, cancer- and family history. This registry will serve as a base for future studies.

2. A surveillance program for adults including an annual general physical examination according to a standardized protocol and whole-body MRI. Women who have not performed prophylactic mastectomy undergo yearly breast-MRI and breast ultrasound (with 6 months' shift). Individuals up to 15 years old will be offered a protocol including ultrasound of the abdomen, urine corticosteroid profile and regular visits to a paediatrician every 3 months (Fig. 2). Those aged 15-18 years may take part in the MRI monitoring (if they are verified TP53 mutation carriers) or continue within the childhood protocol. See Fig. 1 and 2.

3. A biobank is being established at the Karolinska University Laboratory where DNA and plasma from peripheral blood is stored. If a participant develops cancer, fibroblasts from cultured skin biopsies and DNA from tumour samples are collected. If possible, circulating tumour cells are stored. Cell free DNA from plasma will be analysed as a 
complement to screening with MRI, with tumour DNA as a reference. The peripheral blood DNA will be used to identify modifying factors that might explain the difference in phenotype between different families. If functional analyses are needed, RNA or protein from cultured fibroblasts will be used.

4. Patient reported outcomes (PROM) will be assessed concerning health related quality of life (HRQoL) using the Short Form (36) Health Survey [19], the Cancer worry scale [20] and the Risks and benefits of surveillance [21] in order to evaluate the psychosocial impact of participation in the surveillance program. A questionnaire of risk factors for cancer will be used to identify possible environmental modifying factors. Individuals below 18 years of age are not included in the PROM evaluation.

\section{Patient recruitment in the surveillance program}

All individuals, regardless of age, who have been found to be carriers of clinically actionable germline TP53 variants are offered inclusion in SWEP53 via the six regional clinical cancergenetic departments in Sweden (Umeå, Uppsala, Stockholm, Linköping, Gothenburg, and Lund). The families enrolled all have a class 5 variant, or a class 4 with a suggestive class 5 variant (due to for example segregationa analysis in the family) according to the international guidelines of the American College of Medical Genetics (ACMG). All patients have received genetic counselling prior to inclusion. The aim is to offer inclusion in SWEP53 to all known germline TP53 families in Sweden.

Three patients were included during 2016 in order to evaluate the feasibility of the protocol.

\section{Designation of TP53 variants}

There are ongoing discussions if class 4 (likely pathogenic) and 5 (pathogenic) germline variants should be referred to as disease causing or clinically actionable. In the upcoming guideline for TP53 written by ERN GENTURIS, the term disease causing is used (oral communication). However, due to the aspect that the function of risk genes is also dependent on other factors within their cellular pathways, the ability to cause a disease is highly dependent on the genetic environment for their action. Therefore, we chose to use the term clinically actionable rather than disease causing. A clinically actionable variant thus have an impact on recommendatons concerning surveillance as well as treatment.

\section{Inclusion criteria}

- Adults $>18$ years old with a verified known clinically actionable germline variant in TP53.

- Youths aged 15-18 years old may choose to be included in either the adult or child protocol for surveillance.

- Children 0-15 years old with a 50\% risk of being a carrier (i.e. having one parent with a known clinically actionable germline TP53 variant). In order to avoid families feeling forced to genetically test their children in order to take part in SWEP53, the Childhood Solid Tumour Working Group opted to include all children with 50\% risk. Thus, the participants of the childhood protocool do not have to be confirmed carriers.

\section{Exclusion criteria for the surveillance part}

- Contraindications to MRI.

- Co-morbidity that precludes treatment of a cancer found in the surveillance program.

This multi-centre study has been approved by the Regional Ethical Committee/Board in Stockholm, Dnr: 2015/1600-3 and amendments 2017/1527-32 and 2018/

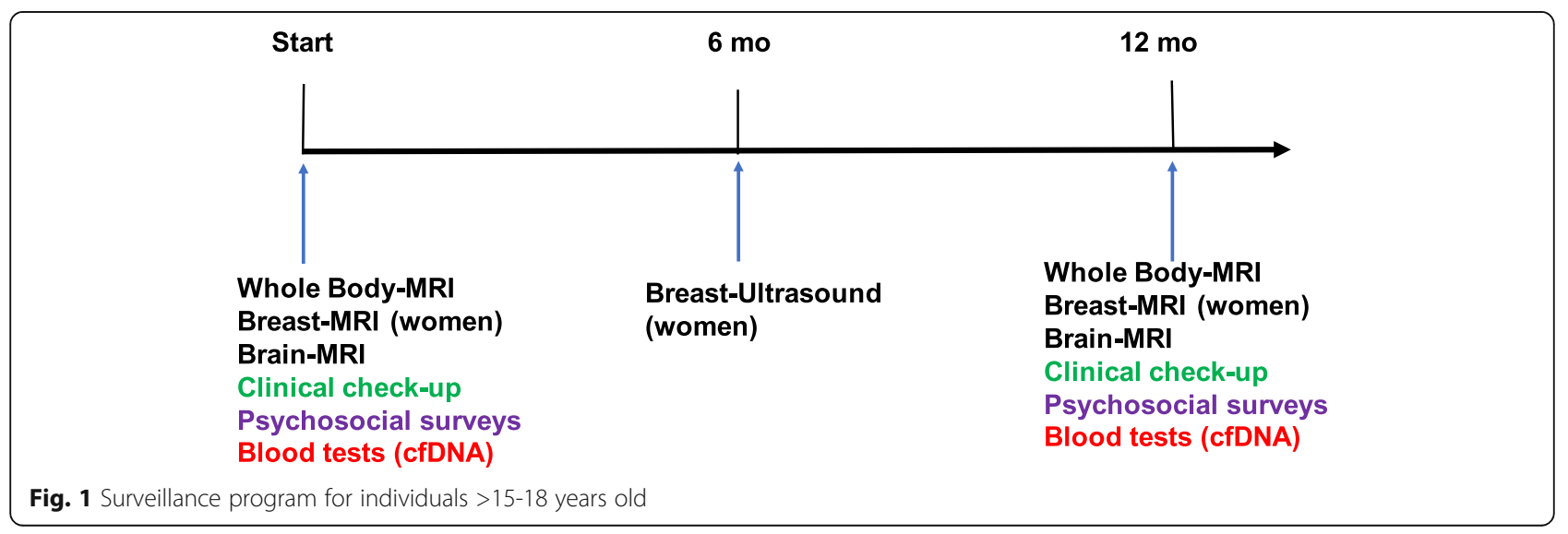




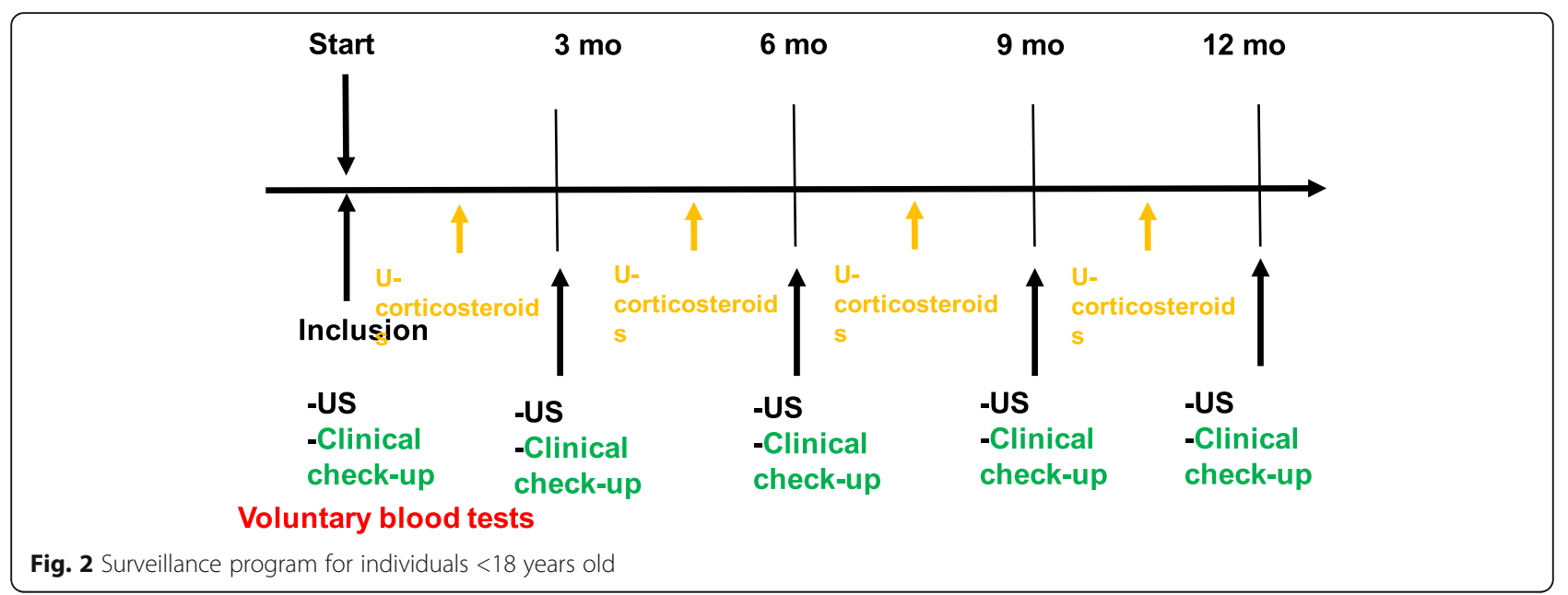

1690-32. Written informed consent is obtained from participants and/or their families.

\section{Study outcomes/aims}

The aims of the prospective observational nationwide multi-centre SWEP53 study are to:

- Evaluate the rate of benign findings and further work-up generated by baseline whole-body MRI.

- Describe the number and pTNM stage of detected malignant lesions and the rate of curative versus palliative intention of treatment.

- pTNM staging will be described and compared to population data.

- Evaluate the psychosocial impact of taking part of the surveillance program and as well as the benefits and risks of participation over time.

- To identify genetic and environmental modifying factors that might impact the phenotype.

- To evaluate cell free DNA and circulating tumour cells (liquid biopsies) as a complement to MRI surveillance in adults with a high risk of cancer.

A Swedish clinical study group including clinical geneticists, oncologists, paediatricians, psychologist, and radiologists was formed in 2012 to plan the outline of the SWEP53. The Swedish surveillance program is modified from the so called Toronto protocol [22].

\section{Imaging}

The yearly WB-MRI examinations covered initially skull base to just below patella, based on initial clinical standard settings, but were during 2017 extended to cover skull base to feet. For males and females who have undergone prophylactic mastectomy, the WB-MRI and brain MRI are performed without contrast enhancement.
For females who undergo breast MRI which requires contrast enhancement, a contrast-enhanced protocol is used, (Additional file 1). The breast ultrasounds are performed in accordance with clinical procedure.

\section{Image acquisition}

The WB-MRI are performed on either 1.5 or 3 Tesla (T) systems. Further details regarding the imaging protocol as set up at Karolinska University Hospital are enclosed in Additional file 1. Technical improvements in MRI during the past decade, DIXON based sequences for rapid whole-body imaging as well as whole-body diffusion weighted imaging, have been implemented into the SWEP53 protocol. Contrast enhancement is only used for the women during breast MRI. The complete imaging protocol takes $90 \mathrm{~min}$ for women including breast MRI and $45 \mathrm{~min}$ for men.

\section{Evaluation}

The whole-body, breast and brain scans are read by two radiologists. Findings requiring further work-up are discussed at a multidisciplinary team meeting, set up by the investigators. All body sites are systematically evaluated for benign and possible malignant findings (see protocol as Additional file 2).

\section{Results \\ Patients}

So far, (December 2019), all 41 adult patients (100\%) who have been informed about the study have accepted inclusion in SWEP53. All the adults, except one (98\%) have chosen to participate in all four parts of the study. Eleven children have been included, of whom five are tested, and participate in the surveillance. Six are not tested, of whom three are under surveillance. 


\section{Discussion}

The rationale behind the Swedish surveillance program The Swedish surveillance program started to be developed during 2012 by the Swedish Clinical TP53 Study Group in a dialogue with national expert groups including the Swedish Society of Oncology, Swedish Society of Radiology and Swedish Childhood Solid Tumour Working Group. The Toronto protocol [22] was the only published MRI protocol for this patient group at the time (2012). A comparison between the protocols is presented in Tables 1 and 2. The Toronto protocol included colonoscopy every 2 years, whereas this is not a part of our protocol due to the lack of evidence for colorectal cancer to be a part of the germline TP53 associated tumours. We have chosen to perform these additional examinations only if they are indicated after a review of the patient's family history since the risk of colorectal cancer in LFS is low [14, 23-25].

Germline TP53-carriers have a high risk of radiation-induced secondary malignancies and patients in SWEP53 are therefore not subjected to mammography in order to minimize exposure to radiation [8, 26, 27]. Instead, MRI and ultrasound are alternated, examining the breasts radiologically once every six months. Patients that have undergone a risk reducing breast surgery do not perform specific breast surveillance.

The Swedish Clinical TP53 Study Group decided not to include blood tests as part of the screening, partly in order to keep the protocol as non-invasive as possible for children and partly because of the difficulties to, in the case of acute leukaemia, diagnose emerging disease prior to clinical symptoms. The time from first detectable blood clone to clinical symptoms can be very short (under a few weeks). It is also challenging to distinguish between age-related clonal haematopoiesis and leukaemia [28]. Therefore, it was decided to focus the surveillance of children on the four core tumours.

\section{Study design of SWEP53}

The surveillance within the SWEP53 study is intended to proceed for five years, and due to prospective incusion the study i opened until 2026. The outline is similar to the Dutch LiFe-Guard study [16]. This is in contrast to the British SIGNIFY study, where patients performed one baseline screening only with matched controls [17]. The randomized clinical trial, the French LIFSCREEN study, includes a follow-up of 48 months [18]. In the present study, surveillance is offered to all known mutation carriers, because of the ethical problems included in motivating randomization in the setting of a known high life-time risk of cancer development. In addition, randomization on an individual basis would be difficult, as members of the same family could be assigned to surveillance or not, probably causing negative psychological effects. If favourable, the SWEP53 protocol will be considered as standard care in Sweden for individuals with germline TP53 alterations.

\section{Rationale to include families with hereditary breast cancer in SWEP53}

One of the aims of SWEP53 is to delineate the cancer risks and potential modifying factors in the two phenotypic groups of germline TP53 carriers, namely the LFS phenotype and the hereditary breast cancer phenotype. A meta-analysis [12] found the prevalence of germline TP53 mutations to be $7.7 \%$ in women with breast cancer $<30$ years old without a LFS family history, and a $7 \%$ prevalence of TP53 mutations amongst women $<31$ years old with a HER2-positive breast cancer. Thus, TP53 correlated breast cancer is more likely to be HER2 positive. In a review by Daly et al, 2017, the overall rate

Table 1 The Toronto and the SWEP53 protocol for children

\begin{tabular}{|c|c|c|c|c|}
\hline \multirow[t]{4}{*}{$\begin{array}{l}\text { The } \\
\text { Toronto } \\
\text { protocol } \\
\text { (2011) } \\
\text { children }\end{array}$} & Adrenocortical carcinoma & Brain tumor & $\begin{array}{l}\text { Soft tissue and bone } \\
\text { sarcoma }\end{array}$ & Leukaemia or lymphoma \\
\hline & $\begin{array}{l}\text { Ultrasound of abdomen and pelvis every 3-4 } \\
\text { months }\end{array}$ & Annual brain MRI & $\begin{array}{l}\text { Annual rapid total body } \\
\text { MRI }\end{array}$ & $\begin{array}{l}\text { Blood test every } 4 \text { months: } \\
\text { complete blood count, } \\
\text { erythrocyte sedimentation rate, } \\
\text { lactate dehydrogenase }\end{array}$ \\
\hline & Complete urinalysis every $3-4$ months & & & \\
\hline & $\begin{array}{l}\text { Blood tests every } 4 \text { months: } \beta \text {-human chori- } \\
\text { onic gonadotropin, alpha-fetoprotein, } 17-\mathrm{OH} \text { - } \\
\text { progesterone, testosterone, dehydroepiandros- } \\
\text { terone sulfate, and rostenedione }\end{array}$ & & & \\
\hline $\begin{array}{l}\text { The } \\
\text { SWEP53 } \\
\text { Protocol } \\
\text { children }\end{array}$ & $\begin{array}{l}\text { Ultrasound of abdomen and pelvis every } 3-4 \\
\text { months } \\
\text { Complete urinalysis every } 3-4 \text { months }\end{array}$ & $\begin{array}{l}\text { None unless suspicion } \\
\text { raised at the clinical } \\
\text { check-up performed } \\
\text { every } 3 \text { months }\end{array}$ & $\begin{array}{l}\text { None unless suspicion } \\
\text { raised at the clinical } \\
\text { check-up performed } \\
\text { every } 3 \text { months }\end{array}$ & $\begin{array}{l}\text { None unless suspicion raised at } \\
\text { the clinical check-up performed } \\
\text { every } 3 \text { months }\end{array}$ \\
\hline
\end{tabular}


Table 2 The Toronto and the SWEP53 protocol for adults

\begin{tabular}{|c|c|c|c|c|c|c|}
\hline $\begin{array}{l}\text { The } \\
\text { Toronto } \\
\text { protocol } \\
\text { (2011) } \\
\text { Adults }\end{array}$ & Breast cancer & $\begin{array}{l}\text { Brain } \\
\text { tumor }\end{array}$ & $\begin{array}{l}\text { Soft tissue } \\
\text { and bone } \\
\text { sarcoma }\end{array}$ & Leukaemia or lymphoma & Colon cancer & Melanoma \\
\hline & $\begin{array}{l}\text { Monthly breast self-examination } \\
\text { starting at age } 18 \text { years }\end{array}$ & $\begin{array}{l}\text { Annual } \\
\text { brain } \\
\text { MRI }\end{array}$ & $\begin{array}{l}\text { Annual rapid } \\
\text { total body } \\
\text { MRI }\end{array}$ & $\begin{array}{l}\text { Blood test every } 4 \text { months: } \\
\text { complete blood count, } \\
\text { erythrocyte sedimentation } \\
\text { rate, lactate } \\
\text { dehydrogenase }\end{array}$ & $\begin{array}{l}\text { Colonoscopy every } 2 \text { years, } \\
\text { beginning at age } 40 \text { years, or } \\
10 \text { years before the earliest } \\
\text { known colon cancer in the } \\
\text { family }\end{array}$ & $\begin{array}{l}\text { Annual } \\
\text { dermatological } \\
\text { examination }\end{array}$ \\
\hline & $\begin{array}{l}\text { Clinical breast examination twice a } \\
\text { year, starting at age } 20-25 \text { years, or } \\
5-10 \text { years before the earliest } \\
\text { known breast cancer in the family }\end{array}$ & & $\begin{array}{l}\text { Ultrasound } \\
\text { of abdomen } \\
\text { and pelvis } \\
\text { every } 6 \\
\text { months }\end{array}$ & & & \\
\hline & $\begin{array}{l}\text { Annual mammography and breast } \\
\text { MRI screening starting at age } 20- \\
25 \text { years, or at earliest age of onset } \\
\text { in the family }\end{array}$ & & & & & \\
\hline & $\begin{array}{l}\text { Consider risk-reducing bilateral } \\
\text { mastectomy }\end{array}$ & & & & & \\
\hline \multirow{5}{*}{$\begin{array}{l}\text { The } \\
\text { SWEP53 } \\
\text { Protocol } \\
\text { Adults }\end{array}$} & Breast cancer & $\begin{array}{l}\text { Brain } \\
\text { tumor }\end{array}$ & $\begin{array}{l}\text { Soft tissue } \\
\text { and bone } \\
\text { sarcoma }\end{array}$ & Leukemia or lymphoma & Colon cancer & Melanoma \\
\hline & $\begin{array}{l}\text { Monthly breast self-examination } \\
\text { starting at age } 18 \text { years }\end{array}$ & $\begin{array}{l}\text { Annual } \\
\text { brain } \\
\text { MRI }\end{array}$ & $\begin{array}{l}\text { Whole-body } \\
\text { MRI }\end{array}$ & $\begin{array}{l}\text { Only if there are known } \\
\text { cases in the family }\end{array}$ & $\begin{array}{l}\text { Only if there are known cases } \\
\text { in the family. } 10 \text { years before } \\
\text { the earliest known colon } \\
\text { cancer in the family }\end{array}$ & $\begin{array}{l}\text { Annual } \\
\text { dermatological } \\
\text { examination }\end{array}$ \\
\hline & $\begin{array}{l}\text { Clinical breast examination once a } \\
\text { year, starting at age } 18\end{array}$ & & & & & \\
\hline & $\begin{array}{l}\text { Annual breast MRI screening } \\
\text { starting at age } 18 \text { and breast } \\
\text { ultrasounds } 6 \text { month after the MRI }\end{array}$ & & & & & \\
\hline & $\begin{array}{l}\text { Consider risk-reducing bilateral } \\
\text { mastectomy }\end{array}$ & & & & & \\
\hline
\end{tabular}

of TP53 carriers was found to be between 0 and $4.4 \%$ amongst tested women with breast cancer. Half of these women did not fulfil LFS NCCN 2017 criteria [29]. It is still unknown if de novo mutations appearing in women with breast cancer are associated with a LFS phenotype since the family history is not informative, challenging the genetic counselling in these families. In families with pathogenic TP53 variants seemingly associated with hereditary breast cancer, a LFS phenotype could potentially occur in the next generation. Breast cancer in young adult women is the most common core cancer in LFS. It may thus be the only LFS associated tumour appearing in generations, especially in small families with predominantly females. We therefore decided to offer similar surveillance to both groups in order to detect other tumours at an early stage.

Finding the right level of further work-ups within SWEP53 A previous meta-analysis describes a rate of $30 \%$ of patients with actionable findings at baseline WB-MRI. The rate of benign findings, after further investigations, were
$79 \%$. The remaining were thus malignant of which $87 \%$ were individuals with new cancers [15]. Preliminary results indicate a similar rate in SWEP53. To manage these, a consistent follow-up care flow is important. There is a need to further evaluate the rate of total work-up and secondary findings. The high-risk for cancer development in this group has implications for the need for further work-up (i.e. we might be more willing to take an extra cytology or biopsy sample compared to a normal patient). A finding of unclear significance should perhaps be considered a cancer until proven to be benign. In addition, TP53 mutation carriers are more prone to develop treatment induced malignancies with implications regarding choice of therapy [26, 27, 30]. Special considerations are also needed in order to avoid unnecessary exposure to irradiation. It is therefore crucial to establish a local multidisciplinary on-site team including oncologists, radiologists, paediatricians, genetic counsellors and clinical geneticists in order to offer personalized care. 


\section{Inventory of known TP53 carriers in Sweden}

There is no national registry containing information on all known TP53 carriers and thus the incidence in Sweden is unknown. Only 25 adult carriers are known in the Stockholm area, much less than the expected 100-400 based on the supposed incidence 1:5000-1: 20000 [4], suggesting a huge under-diagnosis of this condition. This is slowly changing as molecular diagnosis including tumour sequencing as part of a pre-treament predictive screening with panel testing is being introduced in clinical routine analysis. Moreover, in Sweden, women with early-onset breast cancer are now routinely screened for germline alterations with a panel including TP53, thus identifying previously unknown carriers in families with hereditary breast cancer rather than the classical LFS tumour panorama.

\section{Genetic counselling and psychological aspects}

The patients who are offered participation in the SWEP53 study have undergone genetic counselling at the departments of clinical genetics at the participating sites prior to testing and when the results was presented. These patients have experiences of cancer in close relatives, often with fatal outcomes. A relatively low prevalence of clinically relevant levels of distress have been reported in patients with LFS after receiving the results of genetic testing [20]. About $25 \%$ of the patients were, however, in need of professional psychosocial support, but this was irrespective of their carrier status and previous history of cancer. Regular breast cancer surveillance has not been found to be associated with psychological burden [21]. A study examining the psychosocial benefits of a comprehensive whole-body screening program for patients with TP53 mutations suggested that the program provided psychological benefit independent of the impact on cancer morbidity and mortality associated with the syndrome [31]. In the SWEP53 study, the patients' evaluation of the program is important to ascertain if the surveillance program adds worry and emotional problems among the participants. We are studying the possible psychosocial consequences of participation, and also perceived benefits and barriers to participation in the program. The participants are offered psychological support if needed during the study period. The results will form the basis of psychosocial care for patients with hereditary TP53 variants undergoing surveillance.

\section{Children}

In several published surveillance programs WB-MRI screening has been included for children, even though it requires general anaesthesia in young ages [18, 32, 33]. In these programs, genetic testing of TP53 in participating children is required. In the SWEP53 study, included children need to have a parent with a pathogenic TP53 variant, but genetic testing is not required. This inclusion criteria was discussed at length with the Childhood Solid Tumour Working Group and the local paediatricians involved in the heath care of children with $\mathrm{Li}$ Fraumeni syndrome. Since there is not yet robust evidence for the benefits of surveillance in children with TP53 variants, we felt it was unethical to demand genetic testing for inclusion in a research study. Presymptomatic testing of healthy children has not been routinely offered to children in Sweden, although this is slowly changing due to increased awareness of genetic testing among health care professionals and the general public. Knowing the mutational status without being able to affect it may have serious implications on family dynamics and psychological development in the child and should therefore not be part of a research study. If a surveillance program shows certain clinical benefit and is introduced in clinical routine for children, then genetic testing will be performed in order to identify children who have inherited a TP53 variant and are thus at risk for cancer.

The children are not asked to complete questionnaires. To the best of our knowledge, validated psychosocial questionnaires for children are not available. In addition, there is a risk that asking children about possible negative psychological consequences might lead to a focus on their possible risk for cancer.

\section{Conclusions}

The SWEP53 study is ongoing and open for inclusion for all patients in Sweden with a clinically actionable germline variant in TP53, regardless of the phenotypic differences amongst the families. Children at a 50\% risk of being a mutation carrier are also eligible for inclusion. These families are thereby offered to take part in the first nationwide surveillance study that also includes patient related outcomes. By establishing a registry and by collecting DNA, plasma and tumour samples, and fibroblasts, we are also creating opportunities for further studies aimed at understanding the mechanisms behind the phenotype variation within the hereditary TP53 cancer syndrome and how to best tailor follow-up.

When it comes to hereditary TP53 variants, each country have a limited number of carriers. Therefore it would be valuable to have cross border studies. However, due to the complexity of the surveillance and the variety of clinical guidelines among countries, we developed a national study. With this publication, we hope to facilitate the establishment of such programs harmonizing with SWEP53 to extend the cohort and thereby increasing the knowledge of the clinical handling of cancer prone carriers, and improving the survival and quality of life. 


\section{Supplementary information}

Supplementary information accompanies this paper at https://doi.org/10. 1186/s13053-020-0133-5.

Additional file 1. Imaging protocol, whole-body MRI.

Additional file 2. Standardised protocol for evaluation of whole-body MRI within SWEP53.

\section{Abbreviations}

cfDNA: Cell free plasma DNA; LFS: The li fraumeni syndrome; PROM: Patient reported outcomes; SWEP53: The swedish TP53 study; TP53: Tumour protein 53; WB-MRI: Whole-body magnetic resonance imaging

\section{Acknowledgements}

We would like to thank the Swedish Clinical TP53 Study Group. Magnus Tengvar, radiologist for interpreting the WB-MRIs. Roberto Vargas, MRI technologist for performing the MRIs. Åke Borg, molecular biologist for interpreting and confirming the variants.

\section{Ethic approval and consent to participate}

The project was approved by the regional ethical review board in Stockholm. Dnr 2015/1600-3 with the amendments 2017/1527-32 and 2018/1690-32. Written informed consent from all patients was obtained. All procedures performed in studies involving human participants were in accordance with the ethical standards of the institutional and/or national research committee and with the 1964 Helsinki declaration and its later amendments or comparable ethical standards.

\section{Authors' contributions}

$\mathrm{MO}$ led the writing of the manuscript. She was also involved in patient recruitment and clinical data acquisition. SBL and ET contributed to conception and design of the study, patient recruitment and clinical data acquisition. AKS was involved in patient recruitment. YB, LB, PK and NP contributed to the design of the study. All authors revised, read and approved the final manuscript.

\section{Funding}

Funding has been received from the Swedish Cancer Society, The King Gustaf V Jubilee Fund, Stockholm County Council and The Swedish Childhood Fund, Breast Cancer Theme Center at Karolinska University Hospital. Open access funding provided by Karolinska Institute.

\section{Availability of data and materials}

not applicable (no data).

\section{Consent for publication}

not applicable (no data).

\section{Competing interests}

Lennart Blomqvist is co-founder of Collective Minds Radiology. The other authors declare that they have no conflict of interest.

\section{Author details}

${ }^{1}$ Department of Oncology-Pathology, Karolinska Institutet SE-171 77 Stockholm, Sweden AND Cancer Theme, Karolinska University Hospital, Solna, SE-171 76 Stockholm, Sweden. ${ }^{2}$ Department of Molecular Medicine and Surgery, Karolinska Institutet, SE-171 77 Stockholm, Sweden. ${ }^{3}$ Department of Imaging and Physiology Karolinska University Hospital, Solna, SE-171 76 Stockholm, Sweden. ${ }^{4}$ Department of Oncology-Pathology, Karolinska Institutet, SE-171 64 Stockholm, Sweden. ${ }^{5}$ Department of Women's and Children's Health, Karolinska Institutet, SE-171 77 Stockholm, Sweden. ${ }^{6}$ Children and Women's Health Theme, Karolinska University Hospital Solna, SE-171 76 Stockholm, Sweden. ${ }^{7}$ Cancer Theme, Karolinska University Hospital, Solna, SE-171 76 Stockholm, Sweden. ${ }^{8}$ Department of Molecular Medicine and Surgery, Karolinska Institutet, SE-171 77 Stockholm, Sweden.

${ }^{9}$ Department of Clinical Genetics, Karolinska University Hospital Solna, SE-171 76 Stockholm, Sweden.
Received: 19 October 2019 Accepted: 5 January 2020

Published online: 13 January 2020

\section{References}

1. Li FP, Fraumeni JF. Soft-tissue sarcomas, breast cancer, and other neoplasms. A familial syndrome? Ann Intern Med. 1969;71(4):747-52.

2. Varley JM, Evans DG, Birch JM. Li-Fraumeni syndrome--a molecular and clinical review. Br J Cancer. 1997;76(1):1-14. https://doi.org/10.1038/bjc.1997.328.

3. Menendez D, Inga A, Resnick MA. The expanding universe of p53 targets. Nat Rev Cancer. 2009;9(10):724-37. https://doi.org/10.1038/nrc2730.

4. Olfson $\mathrm{E}$, Cottrell CE, Davidson NO, et al. Identification of medically actionable secondary findings in the 1000 genomes. PLoS One. 2015;10(9): e0135193. https://doi.org/10.1371/journal.pone.0135193.

5. Chompret $A$, Brugières $L$, Ronsin $M$, et al. P53 germline mutations in childhood cancers and cancer risk for carrier individuals. Br J Cancer. 2000; 82(12):1932-7. https://doi.org/10.1054/bjoc.2000.1167.

6. Wu C-C, Shete $\mathrm{S}$, Amos Cl, Strong LC. Joint effects of germ-line p53 mutation and sex on cancer risk in Li-Fraumeni syndrome. Cancer Res. 2006; 66(16):8287. https://doi.org/10.1158/0008-5472.CAN-05-4247.

7. Hwang SJ, Lozano G, Amos Cl, Strong LC. Germline p53 mutations in a cohort with childhood sarcoma: sex differences in cancer risk. Am J Hum Genet. 2003;72(4):975-83. https://doi.org/10.1086/374567.

8. Bougeard G, Renaux-Petel M, Flaman JM, et al. Revisiting Li-Fraumeni syndrome from TP53 mutation carriers. J Clin Oncol. 2015;33(21):2345-52. https://doi.org/10.1200/JCO.2014.59.5728.

9. Gonzalez KD, Noltner KA, Buzin CH, et al. Beyond Li Fraumeni syndrome: clinical characteristics of families with p53 germline mutations. J Clin Oncol. 2009:27(8):1250-6. https://doi.org/10.1200/JCO.2008.16.6959.

10. Hisada M, Garber JE, Li FP, Fung CY, Fraumeni JF. Multiple primary cancers in families with Li-Fraumeni syndrome. J Natl Cancer Inst. 1998;90(8):606-11. https://doi.org/10.1093/jnci/90.8.606.

11. Malkin D. Li-fraumeni syndrome. Genes Cancer. 2011;2(4):475-84. https://doi. org/10.1177/1947601911413466.

12. Fortuno $C$, James PA, Spurdle AB. Current review of TP53 pathogenic germline variants in breast cancer patients outside Li-Fraumeni syndrome. Hum Mutat: DOI. 2018. https://doi.org/10.1002/humu.23656.

13. Bajalica Lagercrantz S (2019) Oral communication.

14. Villani A, Shore A, Wasserman JD, et al. Biochemical and imaging surveillance in germline TP53 mutation carriers with Li-Fraumeni syndrome: 11 year follow-up of a prospective observational study. Lancet Oncol. 2016; 17(9):1295-305. https://doi.org/10.1016/S1470-2045(16)30249-2.

15. Ballinger $M L$, Best $A$, Mai $P L$, et al. Baseline surveillance in Li-Fraumeni syndrome using whole-body magnetic resonance Imaging: A Meta-analysis. JAMA Oncol. 2017. https://doi.org/10.1001/jamaoncol.2017.1968.

16. Ruijs MWG, Loo CE, van Buchem CAJM, Bleiker EMA, Sonke GS. Surveillance of Dutch patients with Li-Fraumeni syndrome: the LiFe-guard study. JAMA Oncol. 2017;3(12):1733-4. https://doi.org/10.1001/jamaoncol.2017.1346.

17. Saya S, Killick E, Thomas S, et al. Baseline results from the UK SIGNIFY study: a whole-body MRI screening study in TP53 mutation carriers and matched controls. Familial Cancer. 2017;16(3):433-40. https://doi.org/10.1007/s10689017-9965-1

18. Caron O, Frebourg T, Benusiglio PR, Foulon S, Brugières L. Lung adenocarcinoma as part of the Li-Fraumeni syndrome Spectrum: preliminary data of the LIFSCREEN randomized clinical trial. JAMA Oncol. 2017;3(12):1736-7. https://doi.org/10.1001/jamaoncol.2017.1358.

19. Sullivan M, Karlsson J, Ware JE. The Swedish SF-36 health surveyevaluation of data quality, scaling assumptions, reliability and construct validity across general populations in Sweden. Soc Sci Med. 1995:41(10): 1349-58. https://doi.org/10.1016/0277-9536(95)00125-Q.

20. Lammens CRM, Aaronson NK, Wagner A, et al. Genetic testing in LiFraumeni syndrome: uptake and psychosocial consequences. J Clin Oncol Official J Am Soc Clin Oncol. 2010;28(18):3008. https://doi.org/10.1200/JCO 2009.27.2112.

21. Lammens $\mathrm{C}$, Bleiker $\mathrm{E}$, Aaronson N, et al. Regular surveillance for Li-fraumen syndrome: advice, adherence and perceived benefits. Familial Cancer. 2010; 9(4):647-54. https://doi.org/10.1007/s10689-010-9368-z.

22. Villani A, Tabori U, Schiffman J, et al. Biochemical and imaging surveillance in germline TP53 mutation carriers with Li-Fraumeni syndrome: a prospective observational study. Lancet Oncol. 2011;12(6):559-67. https:// doi.org/10.1016/S1470-2045(11)70119-X 
23. Wong P, Verselis SJ, Garber JE, et al. Prevalence of early onset colorectal cancer in 397 patients with classic Li-Fraumeni syndrome. Gastroenterol. 2006;130(1):73-9. https://doi.org/10.1053/j.gastro.2005.10.014.

24. Mai PL, Best AF, Peters JA, et al. Risks of first and subsequent cancers among TP53 mutation carriers in the National Cancer Institute Li-Fraumeni syndrome cohort. Cancer. 2016;122(23):3673-81. https://doi.org/10.1002/ cncr.30248.

25. Macfarland SP, Zelley K, Long JM, et al. Earlier colorectal Cancer screening may be necessary in patients with Li-Fraumeni syndrome. Gastroenterol. 2019;156, 273(1). https://doi.org/10.1053/.j.gastro.2018.09.036.

26. Evans DG, Birch JM, Ramsden RT, Sharif S, Baser ME. Malignant transformation and new primary tumours after therapeutic radiation for benign disease: substantial risks in certain tumour prone syndromes. J Med Genet. 2006;43(4):289-94. https://doi.org/10.1136/jmg.2005.036319.

27. Heymann S, Delaloge $S$, Rahal A, et al. Radio-induced malignancies after breast cancer postoperative radiotherapy in patients with Li-Fraumeni syndrome. Radiat Oncol. 2010:5:104. https://doi.org/10.1186/1748-717X-5-104.

28. Genovese G, Kähler AK, Handsaker RE, et al. Clonal hematopoiesis and blood-cancer risk inferred from blood DNA sequence. N Engl J Med. 2014; 371(26):2477-87. https://doi.org/10.1056/NEJMoa1409405.

29. Daly MB, Pilarski R, Berry M, et al. NCCN guidelines insights: genetic/familial high-risk assessment: breast and ovarian, version 2.2017. Journal of the National Comprehensive Cancer Network : JNCCN 15(1): 9. 2017. https://doi. org/10.6004/jnccn.2017.0003.

30. Limacher JM, Frebourg T, Natarajan-Ame S, Bergerat JP. Two metachronous tumors in the radiotherapy fields of a patient with Li-Fraumeni syndrome. Int J Cancer. 2001;96(4):238-42.

31. McBride KA, Ballinger ML, Schlub TE, et al. Psychosocial morbidity in TP53 mutation carriers: is whole-body cancer screening beneficial? Familial Cancer. 2017;16(3):423-32. https://doi.org/10.1007/s10689-016-9964-7.

32. Daniele P, Marcos Duarte G, Kelvin César de A, Amanda França N, Rubens C, Maria Isabel A. Whole-body magnetic resonance imaging of Li-Fraumeni syndrome patients: observations from a two rounds screening of Brazilian patients. Cancer Imaging. 2018;18(1):1-8. https://doi.org/10.1186/s40644018-0162-8.

33. Bojadzieva J, Amini B, Day S, et al. Whole body magnetic resonance imaging (WB-MRI) and brain MRI baseline surveillance in TP53 germline mutation carriers: experience from the Li-Fraumeni syndrome education and early detection (LEAD) clinic. Familial Cancer. 2018;17(2):287-94. https:// doi.org/10.1007/s10689-017-0034-6.

\section{Publisher's Note}

Springer Nature remains neutral with regard to jurisdictional claims in published maps and institutional affiliations.

Ready to submit your research? Choose BMC and benefit from:

- fast, convenient online submission

- thorough peer review by experienced researchers in your field

- rapid publication on acceptance

- support for research data, including large and complex data types

- gold Open Access which fosters wider collaboration and increased citations

- maximum visibility for your research: over $100 \mathrm{M}$ website views per year

At $\mathrm{BMC}$, research is always in progress.

Learn more biomedcentral.com/submissions 